\title{
ELEMENTS OF SPACE ORGANIZATION MANAGEMENT OF ENTERPRISES IN THE METAL MATERIALS INDUSTRY
}

\author{
Adrian Ioana, Monica Iorga (Craciunica), Florin-Stefan Petcu, Dumitru Deonise, Daniela Ionela \\ Juganaru, Roxana Marina Solea, Bianca Cezarina Ene
}

University Politehnica of Bucharest-Romania, Department of Engineering and Management of Metallic Materials

Obtaining, Spl. Independentei, No. 313, 060442, Bucharest, Romania

Corresponding author: Adrian Ioana, adyioana@gmail.com

\begin{abstract}
The article has as a starting point the presentation and analysis of the advantages of spatial organization of enterprises, as a management method. Thus, we analyze: creating the optimal conditions for the rhythmic realization of the production process; ensuring greater flexibility in the use of means of production; the possibility of carrying out a maintenance and repair activity of the equipment without disturbing the technological production process; ensuring an efficient management of the production unit. We also analyze, critically and comparatively, the disadvantages of spatial organization, such as: the need for a high qualification of workers; the need for a very high volume of transport and handling; technical quality control is much more complex in the conditions of a diversified production; the production cycle of manufactured products is long.
\end{abstract}

Key words: Production Management; Space Organization; Electric Arc Furnace; Steel.

\section{INTRODUCTION}

The spatial organization of enterprises is of great importance for the metallic materials industry (metallurgy), given the diversity and complexity of technological processes and related equipment.

In an enterprise in the metallic materials industry can operate sections of: elaboration, foundry, forging, mechanical processing (hot and/or cold), assembly, etc. for the different stages of the technological process related to the products to be made [1-3].

The main results of our research consist in the concept of spatial organization for an electric steelworks, for the elaboration of steel in electric arc furnaces.

Also, based on the principles and methods of spatial organization of enterprises in the metallic materials industry, we present and analyze the biunivocal relationship between functional and constructive changes related to specific technologies and equipment (machinery, aggregates).

Among the principles and methods of management of spatial organization, we noticed and applied: giving a primordial importance to the technological purpose; the technological prescriptions (conditionings) are subordinated to the achievement of the proposed technological goal:

$>$ obtaining (achieving) the technological prescriptions is done through the conception and implementation of the afferent functional and constructive modernizations;

$>$ functional upgrades require specific constructive upgrades;

$>$ constructive modernizations determine functional modernizations.

An efficient management of the spatial organization of enterprises in the materials industry requires research and design activities, including using mathematical modeling tools, applying the following principles:

$>$ the principle of analogy - involves the observation and competent analysis of modeled reality, using both analogy with other research and logical homology;

$>$ defining the modeled objective - represents the primary stage of the modeling analysis;

$>$ this stage must satisfy both the purpose and the objectives of the system while ensuring their compatibility;

$>$ defining the efficiency criteria - it is a stage conditioned by the correct definition of the system objectives and allows the optimization of the modeling solutions;

$>$ elaboration of options - based on accessing realistic, efficient and original solutions;

- evaluation of variants - depending on the established efficiency criteria; establishing the final solution - based on the comparative analysis of the different solutions to which the modeling leads; the principle of concepts - is based on the concepts of systems theory including the concept of feedback.

Each production section, in turn, will consist of workshops in which machines of the type appropriate 
to the respective technological process will operate. Thus, in an electric steelworks, for example, can be organized sectors (workshops) of: preparation dosing of cargo, processing, casting, stripping, heat treatment, shipping.

Finaly, like [8] „Today we are on the threshold of a new industrial revolution, the revolution by which digital networks are related to operating values in the intelligent factory, and that includes everything from the initial idea, through design, development and manufacture, to maintenance, service and recycling. Industries 4.0 include horizontal integration of data flow between partners, suppliers and customers, as well as vertical integration within the organizations frames - from development to final product. It merges the virtual and the real world."

\section{ADVANTAGES AND DISADVANTAGES OF SPATIAL ORGANIZATION}

The main advantages of applying the principles and methods related to spatial organization are $[4,5]$ :
$>$ Creating the optimal conditions for the rhythmic realization of the production process.

$>$ Ensuring greater flexibility in the use of means of production.

$>$ In case of failure of some equipment, the development of the production process will not be disturbed.

$>$ Ensuring an efficient management of the production unit.

A relevant example of spatial organization, for the concrete case of an electric steel plant is presented in Figure 1.

The spatial organization of enterprises has some disadvantages, among which we must mention:

$>$ Requires a high qualification of workers.

$>$ Requires a very high volume of transport and handling.

$>$ Technical quality control is much more complex in conditions of diversified production.

$>$ The production cycle of manufactured products is long.

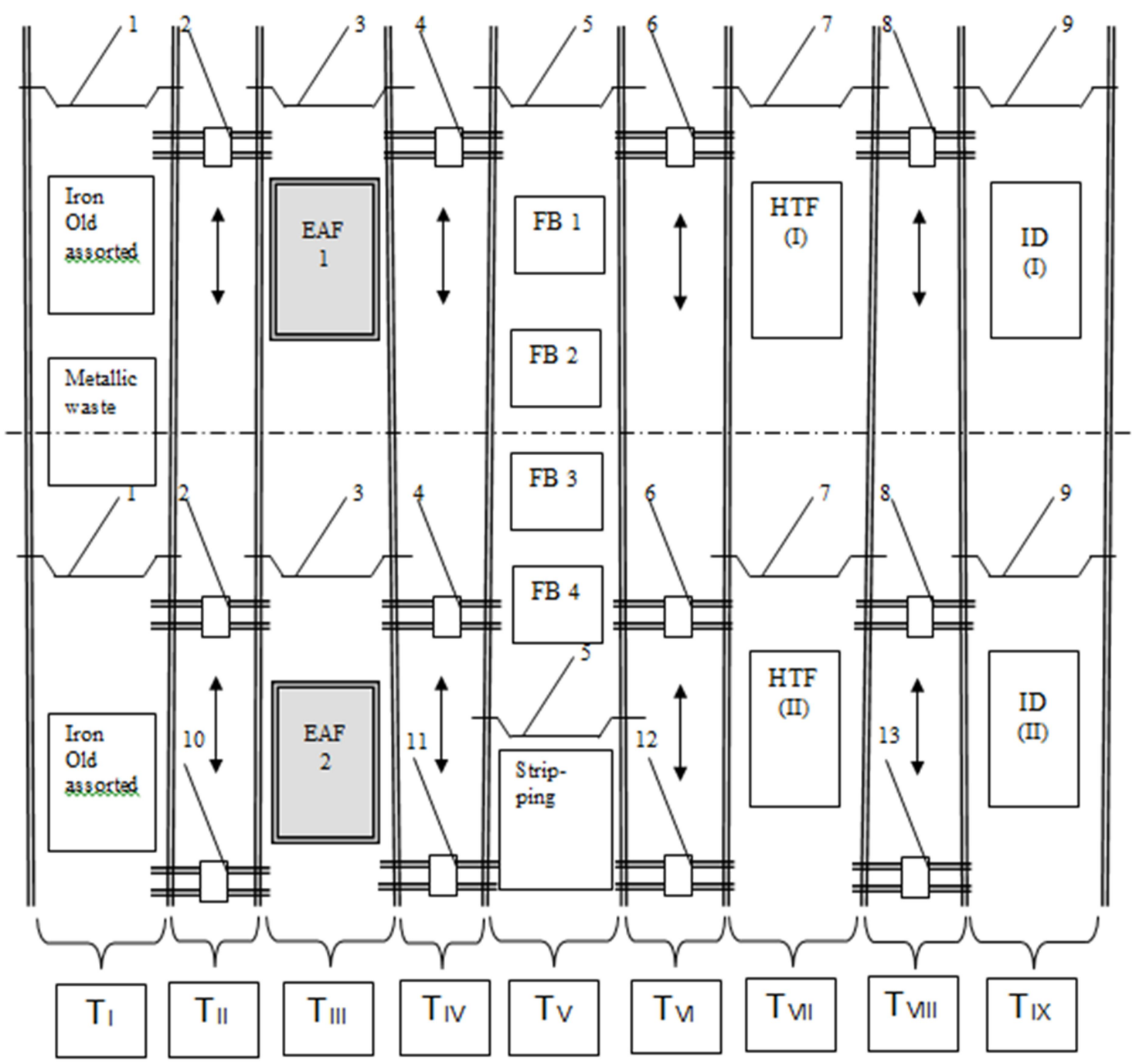

Fig.1. Spatial organization in an electric steelworks 
$\mathrm{T}_{\mathrm{I}}$ - Preparation / Dosing of metal load (beam I).

$\mathrm{T}_{\text {II }}-$ Dosing-elaboration technical space (beam II).

$\mathrm{T}_{\mathrm{III}}-$ Steel processing (beam III).

$\mathrm{T}_{\mathrm{IV}}$ - Technical space for elaboration-casting (beam IV).

$\mathrm{T}_{\mathrm{V}}$ - Casting - tearing (beam V).

$\mathrm{T}_{\mathrm{VI}}$ - Technical space for casting-heat treatment (section VI).

$\mathrm{T}_{\mathrm{VII}}-$ Heat treatment (beam VII).

$\mathrm{T}_{\text {VIII }}$ - Technical space heat treatment-shipping (beam VIII).

$\mathrm{T}_{\mathrm{IX}}$ - Expedition (beam IX).

EAF - Electric arc furnace for steelmaking;

FB - Foundry Bridge;

HTF - Heat Treatment Furnace;

ID - Ingot Depot.

1 - Dosing-load overhead cranes;

2, 10 - Dose-processing transfer;

3 - Casting overhead cranes;

4, 11 - Transfer processing-casting;

5 - Casting-stripping overhead cranes;

6, 12 - Casting transfer -TT;

7 - Cranes TT;

8, 13 - Transfer TT-Expedition;

9 - Expedition overhead cranes.

\section{PRINCIPLES AND METHODS OF SPATIAL ORGANIZATION OF ENTERPRISES IN THE METALLIC MATERIALS INDUSTRY}

The principles and methods of spatial organization of enterprises in the metallurgical industry must be based on the biunivocal relationship between functional and constructive changes related to specific technologies and equipment (machinery, aggregates) [6,7]. This biunivocal relationship is shown schematically in Figure 2.

Among the principles and methods of management of spatial organization are:

$>$ The technological prescriptions (conditionings) are subordinated to the achievement of the proposed technological goal.

$>$ Obtaining (realizing) the technological prescriptions is done through the conception and implementation of the afferent functional and constructive modernizations.

$>$ Functional upgrades require specific constructive upgrades.

$>$ Constructive modernizations determine functional modernizations.

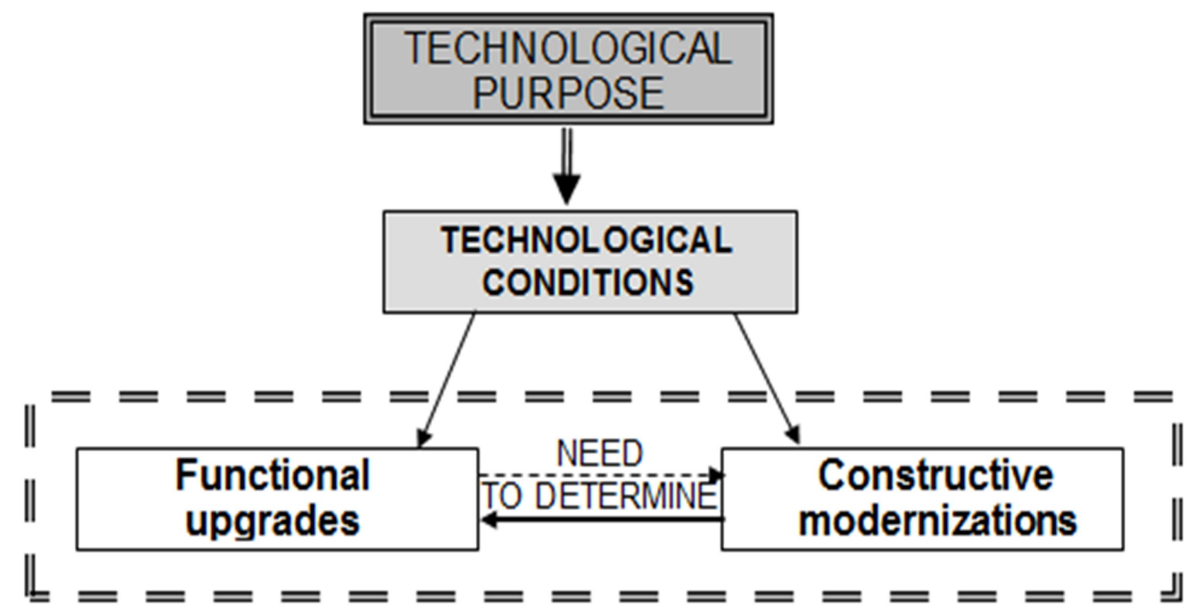

Fig. 2. The biunivocal relationship between functional modernization and constructive modernization (technologically conditioned)

An efficient management of the spatial organization of enterprises in the materials industry requires research and design activities, including using mathematical modeling tools, applying the following principles:

A. The principle of analogy - involves the observation and competent analysis of modeled reality, using both analogy with other fields of research and logical homology.

According to this principle, in order to elaborate mathematical models, the stages must be completed:
> Defining the modeled objective - represents the primary stage of modeling analysis; this stage must satisfy both the purpose and the objectives of the system while ensuring their compatibility.

$>$ Defining efficiency criteria - it is a conditioned stage of the correct definition of the system objectives and allows the optimization of the modeling solutions.

> Elaboration of options - based on accessing realistic, efficient and original solutions. 
Evaluation of variants - depending on the established efficiency criteria.

B. Establishing the final solution - based on the comparative analysis of the different solutions to which the modeling leads.

C.The principle of concepts - it is based on the concepts of systems theory, including the concept of feedback.

D.The principle of hierarchy - implies the need to compile a hierarchical model system, in order to structure the decision and coordinate the interactive subsystems.

E.The principle of uncertainty - it is mainly generated by the high degree of complexity of the technological processes in the metallic materials industry. In addition, the existence of the interaction between the component subsystems - an interaction that cannot always be exactly predetermined - and the existing nonlinearities in the system, the subjectivity of choosing and prescribing the objective function contribute to the increase of uncertainty factors.

It is useful to mention that, based on this modeling principle, as the complexity of the system increases, requiring a hierarchical structure, the developed models decrease in accuracy but increase in the degree of relevance.
F.The principle of the internal model - establishes that a dynamic system is structured stably only if:

$>$ Uses the negative reaction of the adjusted quantities.

$>$ Incorporates in the reaction loop a reduplicated model of the dynamic structure of exogenous signals; this internal model provides the signals meant to asymptotically compensate the disturbances of the analyzed technological system.

The prescription (establishment) of the objective function (FO) of the modeling system of the technological processes in the materials industry is based on the qualitative-economic analysis of these processes. In this sense, the development of a new product (in this case a quality steel brand) must ensure both its profitability and the ability to ensure quality conditions.

The concept of the mathematical model for prescribing the objective function is based on the quantification of the objective function (FO) in the form of a qualitative-economic matrix MCE, according to the scheme presented in Figure 3.

Prescription levels of the objective function are obtained by applying an algorithm for composing three vectors:

- Vector $\overline{\mathrm{T}}$ - vector of technical parameters $\left(\mathrm{t}_{\mathrm{i}}\right)$.

- Vector $\bar{E}$ - vector of economic parameters $\left(\mathrm{e}_{\mathrm{j}}\right)$.

- Vector $\overline{\mathrm{P}}$ - weight vector $\left(\mathrm{p}_{\mathrm{k}}\right)$.

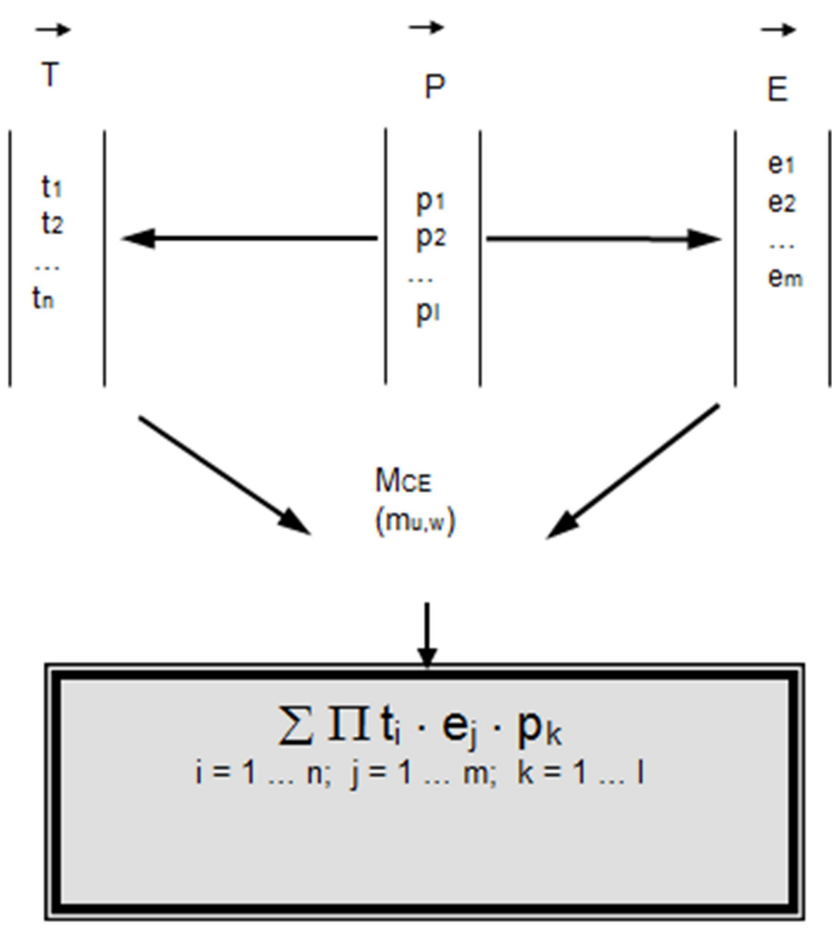

Fig. 3. Quantification of the objective function of the modeling system 
The components of the two vectors $\overline{\mathrm{T}}$ and $\overline{\mathrm{E}}$ considered with important weights in the quantification (prescribing) of the objective function FO is adopted directly dependent on the fixed technological purpose (from which derive the necessary technological).

The following is an example of adopting the components of the two vectors, in the case of the technological process of making electric steel.

Explain of the vectors:

Components of the vector of technical parameters $\left(t_{i}\right)$ :

$>t_{1}-$ chemical composition of the steel (branding accuracy);

$>\mathrm{t}_{2}$ - purity of steel (in gases);

$>\mathrm{t}_{3}$ - purity of steel (in inclusions).

Components of the vector of economic parameters $\left(\mathrm{e}_{\mathrm{j}}\right)$ :

$\mathrm{e}_{1}-$ specific consumption of raw materials and materials;

$>\mathrm{e}_{2}-$ specific energy consumption;

$>\mathrm{e}_{3}$ - productivity of the elaboration process in CAE.

Weight vector $\left(\mathrm{p}_{\mathrm{k}}\right)$ - is a percentage between 0 and 100 , depending on the specific conditions.

In conclusion, the management of the spatial organization of enterprises in the materials industry must take into account both the optimal solution of the internal (internal) organization of the enterprise (location and layout of sections, plants, workshops, aggregates, equipment, etc.) and external organization. This (external organization) refers to optimizing the correlations of the enterprise with its external economic environment.

An important role in the efficiency of the enterprise in its relations with the external economic environment has the assurance of a fluid and continuous supply and sales system. The spatial organization of the enterprise is of decisive importance for the fulfillment of this role.

\section{CONCLUSIONS}

Spatial organization is very important for enterprises in the metal materials industry. From this point of view, we specify that there are scientific disciplines specially allocated to this field, of which we specify "Design of Metallurgical Sectors".

Spatial organization, as a management method, has the following advantages:
Creating the optimal conditions for the rhythmic realization of the production process.

$>$ Ensuring greater flexibility in the use of means of production.

$>$ In case of failure of some equipment, the development of the production process will not be disturbed.

$>$ Ensuring an efficient management of the production unit.

The main principles and methods of management of spatial organization for enterprises in the metal materials industry are: the technological prescriptions (conditionings) are subordinated to the achievement of the proposed technological goal; obtaining (realizing) the technological prescriptions is done through the conception and implementation of the afferent functional and constructive modernizations; functional upgrades require specific constructive upgrades; constructive modernizations determine functional modernizations.

Mathematical modeling has an important role in the spatial organization of enterprises in the metal materials industry. Thus, the following principles must be applied: defining the modeled objective; defining efficiency criteria; elaboration of options; evaluation of variants; establishing the final solution.

\section{REFERENCES}

1. Ioana A, Semenescu A (2015) Tratat de Ştiinţa şi Ingineria Materialelor Metalice, 6, ProiectareCalitatea Produselor-Materiale Speciale-Inginerie Economică Metalurgică, Chapter 5. Inginerie Economică Metalurgică, AGIR Publishing House, ISBN 978-973-720-533-9, ISBN 973-720-064-0, 110.

2. Ioana A (2016), Managementul Producţiei în Industria Materialelor Metalice. Teorie şi Aplicaţii. Edition II, revised and improved, Printech Publishing House, ISBN 978-606-23-0567-3, Bucharest, 246.

3. Marcu D. F., Ioana A, Mates I, Semenescu A, Chiva I.C.and Florea B. (2020), Managementul producerii materialelor metalice. Teorie şi aplicaţii, Matrix ROM Publishing House, ISBN 978-606-250608-7, 127.

4. Ioana A, Tufeanu D, Semenescu A, Mates I. M., Marcu D, Florea B, Solea R, Juganaru D. I., Manolescu D and Ene B. C. (2020), Aspects on 
optimizing the management of production of metallic materials, Proceedings of Conf. ROMAT 2020.

5. Ioana A, Costoiu M, Tufeanu D, Semenescu A and Marcu, D.F., (2019), Management elements of conception and development of scientific research projects, IOP Conf. Series: Materials Science and Engineering 591, 012092, IOP Publishing, Modern Technologies in Industrial Engineering VII, (ModTech2019), doi:10.1088/1757899X/591/1/01209, 1-5.

6. Ionescu S, Păunescu I, (2001), Managementul productiei, Eficient Publishing House, Bucharest.

7. Ioana A, (2013), Noi Descoperiri, Noi Materiale, Noi Tehnologii, Printech Publishing House, ISBN 978-606-23-0069-2, Bucharest, 101.

8. Hozdić E (2015), Smart Factory for Industry 4.0: A Review, International Journal of Modern Manufacturing Technologies, ISSN 2067-3604, Vol. VII, No. 1 / 2015.
Received: April 26, 2021 / Accepted: December 20, 2021 / Paper available online: December 25, 2021 (C) International Journal of Modern Manufacturing Technologies 